\title{
cDNA cloning, characterization and expression analysis of peroxiredoxin 5 gene in the ridgetail white prawn Exopalaemon carinicauda
}

\author{
Yafei Duan $\cdot$ Ping Liu $\cdot$ Jitao Li $\cdot$ Jian Li \\ Baoquan Gao $\cdot$ Ping Chen
}

Received: 21 March 2013/Accepted: 14 September 2013/Published online: 19 October 2013

(C) The Author(s) 2013. This article is published with open access at Springerlink.com

\begin{abstract}
Peroxiredoxin is a superfamily of antioxidative proteins that play important roles in protecting organisms against the toxicity of reactive oxygen species. In this study, a full-length of peroxiredoxin 5 (designated EcPrx5) cDNA was cloned from the ridgetail white prawn Exopalaemon carinicauda by using rapid amplification of cDNA ends (RACE) approaches. The full-length cDNA of the EcPrx 5 was of $827 \mathrm{bp}$, containing a $5^{\prime}$ untranslated region (UTR) of $14 \mathrm{bp}$, a $3^{\prime}$ UTR of 228 bp with a poly (A) tail, and an open reading frame of 585 bp encoding a polypeptide of 194 amino acids with the predicted molecular weight of $20.83 \mathrm{kDa}$ and estimated isoelectric point of 7.62. BLAST analysis revealed that amino acids of EcPrx 5 shared $89,68,66,65,53$ and $51 \%$ identity with that of Macrobrachium rosenbergii, Megachile rotundata, Harpegnathos saltator, Acromyrmex echinatior, Danio rerio, and Homo sapiens counterparts, respectively. The conserved Prx domain and the signature of peroxiredoxin catalytic center identified in EcPrx5 suggested that EcPrx5 belonged to the atypical 2-Cys Prx subgroup. Real time quantitative RT-PCR analysis indicated that EcPrx 5 could be detected in all the tested tissues with highest expression level in hepatopancreas. As time progressed, the expression
\end{abstract}

Y. Duan · P. Liu $(\bowtie) \cdot$ J. Li · J. Li · B. Gao · P. Chen Key Laboratory of Sustainable Development of Marine Fisheries, Ministry of Agriculture, Yellow Sea Fisheries Research Institute, Chinese Academy of Fishery Sciences, 266071 Qingdao, China

e-mail: liuping@ysfri.ac.cn

Y. Duan

Key Laboratory of South China Sea Fishery Resources Exploitation \& Utilization, Ministry of Agriculture, South China Sea Fisheries Research Institute, Chinese Academy of Fishery Sciences, 510300 Guangzhou, China level of EcPrx5 both in hemocytes and hepatopancreas increased in the first $6 \mathrm{~h}$ after Vibrio anguillarum and white spot syndrome virus challenge, and showed different expression profiles. The results indicated that EcPrx5 involved in immune response against bacterial and viral infection in E. carinicauda.

Keywords Exopalaemon carinicauda .

Peroxiredoxin 5 (Prx5) - Gene cloning · Expression

\section{Introduction}

Reactive oxygen species (ROS), such as hydrogen peroxide $\left(\mathrm{H}_{2} \mathrm{O}_{2}\right)$, superoxide anion and singlet oxygen, are thought to be involved in cancer, aging and various inflammatory disorders [1]. In addition, these ROSs can kill foreign invaders efficiently and also play an important role in immune signal transduction [2, 3]. However, the mass accumulation of ROS in animals will cause serious cell damage, resulting in various diseases [4-6]. To protect themselves against damages of ROS, aerobic organisms have developed a set of antioxidant defense systems, including antioxidant enzymes such as superoxide dismutase, catalase and many kinds of peroxidases [7-9].

Peroxiredoxin (Prx) is a large family of antioxidant proteins ubiquitously found from prokaryotes to eukaryotes [5, 10-12], which play important roles in protecting the organisms against oxidative stress and regulating the intracellular signal transduction $[13,14]$. In mammals, six different isoforms of Prx (Prx1-Prx6) have been identified [15, 16]. Based on the number of cysteine residues involved in catalysis and the type of disulfide bond formed, Prxs are divided into three subgroups: 2-Cys (Prx1-Prx4), atypical 2-Cys (Prx5) and 1-Cys (Prx6) [11, 17]. Prx5, also known as 
PrxV, AOEB166, PMP20 or ACR1, is a mammalian thioredoxin peroxidase that can be addressed to mitochondria, peroxisomes and the cytosol, suggesting that this peroxiredoxin may have an important role as antioxidant in organelles [18, 19]. Several Prx5 have been isolated from vertebrate and invertebrate species [20-23]. However, no studies about Prx5 in Exopalaemon carinicauda have been reported till now.

The ridgetail white prawn E. carinicauda is an important economical shrimp species naturally distributed in the coasts of Yellow Sea and Bohai Sea, China [24], which contributes to one-third of the gross outcome of the polyculture ponds in eastern China $[25,26]$. However, various diseases caused by bacteria and viruses have blossomed within booming $E$. carinicauda cultures, causing economic losses to commercial shrimp aquaculture [26]. Better understanding of the innate immune abilities and immune defense mechanisms of shrimp will be beneficial to the development of health management and disease control in shrimp aquaculture. The aim of this study was to clone the full-length cDNA of Prx5 from hemocytes of E. carinicauda, compare its sequence with other known Prx5s from other animals, investigate the expression pattern of EcPrx 5 in various tissues, and evaluate its expression in E. carinicauda with Vibrio anguillarum and white spot syndrome virus (WSSV) challenge.

\section{Materials and methods}

Animal materials

Healthy adult E. carinicauda, averaging weight $1.19 \pm 0.32 \mathrm{~g}$, were collected from a commercial farm in Qingdao, China. They were cultured in filtered aerated seawater (salinity $20 \%, \mathrm{pH} 8.2$ ) at $18 \pm 0.5{ }^{\circ} \mathrm{C}$ for 7 days before processing. There were 30 shrimps in each group. The shrimps were fed daily with a ration of $10 \%$ of body weight, and two-thirds of the water in each group was renewed once daily.

\section{RNA extraction and cDNA synthesis}

Hemocytes were collected with syringe contained an equal volume of anti-coagulant buffer [27], and centrifuged at $800 \mathrm{~g}, 4^{\circ} \mathrm{C}$ for $15 \mathrm{~min}$. Total RNA was extracted from hemocytes using Trizol Reagent (Invitrogen, USA) according to the manufacturer's instruction. The RNA samples were analyzed in $1.0 \%$ agarose electrophoresis and quantitated at $260 \mathrm{~nm}$, all $\mathrm{OD}_{260} / \mathrm{OD}_{280}$ were between 1.8 and 2.0. The $3^{\prime}$ and $5^{\prime}$ ends RACE cDNA template were synthesized using SMART ${ }^{\mathrm{TM}}$ cDNA Kit (Clontech, USA) following the protocol of the manufacturer.
Cloning the full-length cDNA of EcPrx5

An EST sequences was found in large scale EST sequencing from hemocytes cDNA library of the ridgetail white prawn E. carinicauda (GenBank accession no. JK996159), which was constructed using the SMART cDNA library construction kit (Clontech, USA) and have been reported by Duan et al. [24]. Blast analysis showed that they have high similarities with Prx5. According to the EST sequence, a gene specific primer F1 was designed for $3^{\prime}$ RACE, and R1 was designed for $5^{\prime}$ RACE (Table 1).

Based on the partial sequence data of Prx 5 , its $3^{\prime}$ and $5^{\prime}$ ends were obtained using SMART RACE cDNA Amplification Kit (Clontech, USA). For $3^{\prime}$ RACE, the PCR reaction was performed using the primer $\mathrm{F} 1$ and the anchor primer UPM (Table 1). The PCR reaction systems were $50 \mu \mathrm{L}$, including RACE cDNA template $2.5 \mu \mathrm{L}$, $10 \times$ Advantage 2 PCR buffer $5 \mu \mathrm{L}$, dNTP Mix $(10 \mu \mathrm{mol} / \mathrm{L})$ $1 \mu \mathrm{L}, 50 \times$ Advantage 2 Polymerase Mix $1 \mu \mathrm{L}$, primer UPM $(10 \mu \mathrm{mol} / \mathrm{L}) 5 \mu \mathrm{L}$, primer F1 $(10 \mu \mathrm{mol} / \mathrm{L}) 1 \mu \mathrm{L}$, PCR-Grade water $34.5 \mu \mathrm{L}$. The PCR reaction conditions were 5 cycles of $94{ }^{\circ} \mathrm{C}$ for $30 \mathrm{~s}, 72{ }^{\circ} \mathrm{C}$ for $3 \mathrm{~min}, 5$ cycles of $94{ }^{\circ} \mathrm{C}$ for $30 \mathrm{~s}, 70{ }^{\circ} \mathrm{C}$ for $30 \mathrm{~s}$, and $72{ }^{\circ} \mathrm{C}$ for $3 \mathrm{~min}$, and 25 cycles of $94{ }^{\circ} \mathrm{C}$ for $30 \mathrm{~s}, 68{ }^{\circ} \mathrm{C}$ for $30 \mathrm{~s}$ and $72{ }^{\circ} \mathrm{C}$ for 3 min. For $5^{\prime}$ RACE, the PCR reaction was performed using the primer R1 and the anchor primer UPM (Table 1). The PCR reaction systems and conditions were the same as those described above.

The PCR fragments were subjected to electrophoresis on $1.5 \%$ agarose gel to determine length differences, and the target band was purified by PCR purification kit (Promega, USA). The purified products were cloned into PMD18-T vector, following the instructions provided by manufacturer (TaKaRa, Japan). Recombinant bacteria were identified by blue/white screening and confirmed by PCR. Plasmids containing the insert were purified (Promega minipreps) and used as a template for DNA sequencing.

Table 1 Primer sequences used in this study

\begin{tabular}{ll}
\hline Primer & Sequence $\left(5^{\prime}-3^{\prime}\right)$ \\
\hline F1 (forward) & TGGCGACCATTCTCAGTG \\
R1 (reverse) & CTTTAGACTTCGGTTCCT \\
F2 (forward) & AGATTGTTCCACGGTTTTGTG \\
R2 (reverse) & AATACTTTGCGTCCTGCTGAC \\
18 S-HF & TATACGCTAGTGGAGCTGGAA \\
$18 S-H R$ & GGGGAGGTAGTGACGAAAAAT \\
UPM & CTAATACGACTCACTATAGGGCAA \\
& GCAGTGGTATCAACGCAGAGT \\
& CTAATACGACTCACTATAGGGC \\
\hline
\end{tabular}


Sequence analysis

The nucleotide and deduced amino acid sequences of EcPrx 5 cDNA were analyzed and compared using the BLAST search programs (http://www.blast.ncbi.nlm.nih. gov/Blast.cgi). The multiple sequence alignment of Prx5 amino acid sequences was performed using the programs of Vector NTI advance 10.3 (Invitrogen). A phylogenetic $\mathrm{NJ}$ tree of Prxs was constructed by the MEGA 4.0 software [28].

\section{Tissue expression of EcPrx5}

Hemocytes, gill, hepatopancreas, muscle, ovary, eyestalk, stomach and bowel were dissected from unchallenged $E$. carinicauda. The mRNA expressions of EcPrx 5 in different tissues were determined by quantitative real-time RT-PCR. Total RNA was extracted as described above. The RNA samples were analyzed in $1.0 \%$ agarose electrophoresis and quantitated at $260 \mathrm{~nm}$, all $\mathrm{OD}_{260} / \mathrm{OD}_{280}$ were between 1.8 and 2.0. Total RNA $(5 \mu \mathrm{g})$ was reverse transcribed using the PrimeScript ${ }^{\mathrm{TM}}$ Real time PCR Kit (TaKaRa, Japan) for real-time quantitative RT-PCR analysis.

\section{Experimental design of V. anguillarum and WSSV} challenge

The experiments were divided into the bacterial challenged group, the virus challenged group and the control group. V. anguillarum strains was obtained from Germplasm Resources and Genetic Breeding Laboratory, Yellow Sea Fisheries Research Institute, activating on marine agar 2611E. WSSV crude extract were obtained from 10 grams of WSSV-infected tissue from Litopenaeus vannamei, which provided from Mariculture Disease Control and Pathogenic Molecular Biology Laboratory, Yellow Sea Fisheries Research Institute, the methods referred to $\mathrm{Li}$ et al. [29]. In the experiment, the challenged groups were injected individually with $20 \mu \mathrm{L}$ live $V$. anguillarum suspended in $0.9 \%$ normal saline $\left(2 \times 10^{8} \mathrm{CFU} / \mathrm{mL}\right)$ or $20 \mu \mathrm{L}$ WSSV crude extract, the control group received individually an injection of $20 \mu \mathrm{L}$ sterile $0.9 \%$ saline solution. Hemocytes and hepatopancreas of six shrimps from each treatment (the challenged group and the control group) were randomly sampled at $0,3,6,12,24,48$ and $72 \mathrm{~h}$ post-injection respectively, then the samples were snap-frozen in liquid nitrogen. There were three replicates for each time point. Total RNA was extracted and the first strand cDNA was synthesized as described above.
Expression of EcPrx5 after V. anguillarum and WSSV challenge

Real time quantitative RT-PCR was performed on an ABI PRISM 7500 Sequence Detection System (Applied Biosystems, USA) to investigate the expression of EcPrx5. The pair of specific primers F2 and R2 (Table 1) was used to amplify a PCR product of $166 \mathrm{bp}$. Two primers 18S-HF and 18S-HR (Table 1) were used to amplify an $18 \mathrm{~S}$ gene of $147 \mathrm{bp}$ as an internal control to verify the successful reverse transcription and to calibrate the cDNA template. The RT-PCR was carried out in a total volume of $20 \mu \mathrm{L}$, containing $10 \mu \mathrm{L}$ SYBR $^{\circledR}$ Premix Ex Taq ${ }^{\text {TM }}$ II $(2 \times)$ (TaKaRa, Japan), $2 \mu \mathrm{L}$ of the 1:5 diluted cDNA, $0.8 \mu \mathrm{L}$ each of F2 $(10 \mu \mathrm{mol} / \mathrm{L})$ and $\mathrm{R} 2$ primer $(10 \mu \mathrm{mol} / \mathrm{L})$ (or $18 \mathrm{~S}-\mathrm{HF}(10 \mu \mathrm{mol} / \mathrm{L})$ and $18 \mathrm{~S}-\mathrm{HR}$ $(10 \mu \mathrm{mol} / \mathrm{L})$ to amplify the $18 \mathrm{~S}), 0.4 \mu \mathrm{L}$ ROX Reference Dye II $(50 \times) * 3$ and $6 \mu \mathrm{L}$ DEPC-treated water. The PCR program was $95{ }^{\circ} \mathrm{C}$ for $30 \mathrm{~s}$, then 40 cycles of $95{ }^{\circ} \mathrm{C}$ for $5 \mathrm{~s}$ and $60{ }^{\circ} \mathrm{C}$ for $34 \mathrm{~s}$, followed by 1 cycle of $95^{\circ} \mathrm{C}$ for $15 \mathrm{~s}$, $60{ }^{\circ} \mathrm{C}$ for $1 \mathrm{~min}$ and $95{ }^{\circ} \mathrm{C}$ for $15 \mathrm{~s}$. DEPC-treated water for the replacement of template was used as negative control.

RT-PCR data from three replicate samples were analyzed with the ABI 7300 system SDS Software (Applied Biosystems, USA), for estimating transcript copy numbers for each sample. The comparative $C_{\mathrm{T}}$ method was to analyze the relative expression level of EcPrx 5. The $C_{\mathrm{T}}$ for the target amplified products of EcPrx 5 and internal control $18 \mathrm{~S}$ were determined for each sample. Difference in the $C_{\mathrm{T}}$ between the target and the internal control, called $\triangle C_{\mathrm{T}}$, was calculated to normalize the differences in the amount of template and the efficiency of the RT-PCR. In the same challenge time, the $\triangle C_{\mathrm{T}}$ of the control group was used as the calibrator, and the difference between the $\triangle C_{\mathrm{T}}$ of the challenged group and the control group was called $\triangle \triangle C_{\mathrm{T}}$. The expression level of EcPrx5 was calculated by the $2^{-\Delta \Delta C_{\mathrm{T}}}$ comparative $C_{\mathrm{T}}$ method [30].

Statistical analysis was performed using SPSS software (Ver 11.0). Statistical significance was determined using one-way ANOVA [20] and post hoc Duncan multiple range tests. Significance was set at $P<0.05$.

\section{Result}

Sequence characterization of EcPrx 5

The full-length EcPrx5 cDNA of E. carinicauda was obtained by RACE, and the results are shown in Fig. 1. The full-length of EcPrx 5 was $827 \mathrm{bp}$, containing a $585 \mathrm{bp}$ open reading frame (ORF) encoded for 194 amino acids. The cDNA contained a $5^{\prime}$-untranslated region (UTR) of $14 \mathrm{bp}$, a $3^{\prime}$-UTR of $228 \mathrm{bp}$ including a stop codon (TAA) polyadenylation signal (ATAAA) and a poly (A) tail. The calculated molecular mass was $20.83 \mathrm{kDa}$, and the 


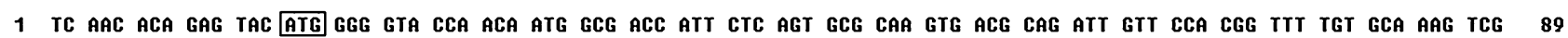
90 CCT TTA GGA ATT IIT ACA GCT CTC AGT CGA GCC ATG TCT AIT AAG GTA GGG GAT GAG ATT CCT AGC GTG GAT TTA TAT GAA GAG ACC CCT 179

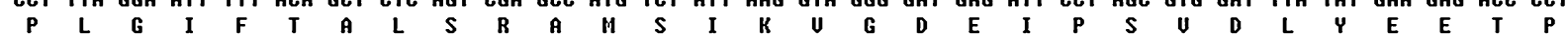
180 GCC AAC ACA GTC AAC CTT CGA GAT GTG TCA GCA GGA CGC AAA GTA TTG GTA TIT GCT GTC CCA GGG GCC TTC ACT CCT GGA TGT TCT AAG 269

\begin{tabular}{llllllllllllllllllllllllllllll}
$A$ & $N$ & $T$ & $U$ & $N$ & $L$ & $R$ & $D$ & $U$ & $S$ & $A$ & $G$ & $R$ & $K$ & $U$ & $L$ & $U$ & $F$ & $A$ & $U$ & $P$ & $G$ & $A$ & $F$ & $T$ & $P$ & $G$ & $C$ & $S$ & $K$ \\
\hline
\end{tabular} 270 ACT CAC CTA CCT GGA TAC ATA AAA CAA GCT GAG GAA CCG AAG TCT AAA GGT ATC AAC GAA ATT ATT TGT GTT GCC GTC AAT GAT CCC TTC 359

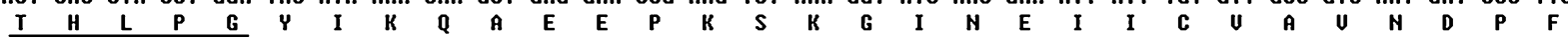

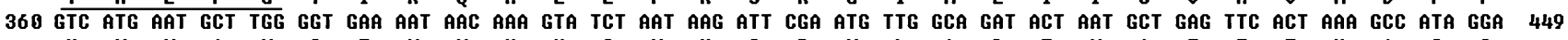
$\begin{array}{llllllllllllllllllllllllllllll}U & M & N & A & V & G & E & N & N & K & U & S & N & K & I & R & M & L & A & D & T & N & A & E & F & T & K & A & I & G\end{array}$

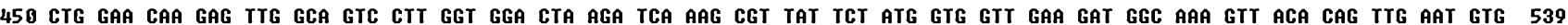

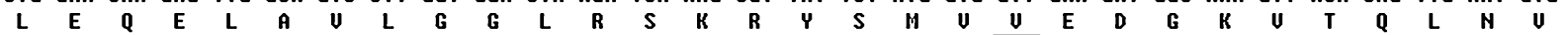

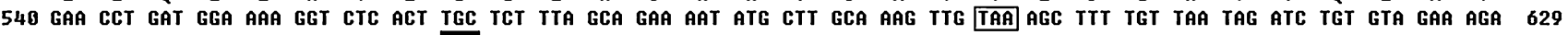
$\begin{array}{llllllllllllllllllllllllllll}E & P & D & G & K & G & L & T & C & S & L & A & E & N & M & L & A & K & L & *\end{array}$ 638 AAA TGT TTA CTG GTG ITA CGT AGA CAC CCT TTA TAT TAT GTA GIT GAG GAG GIT ATG CAT TTA TGA ITT AGT GAT ATC ITC TGT TAC AGT 719 728 GTA TIT TGT AAT GTA AGA GGT AGA GTG TAA TAC TTG CTT GTG TIT TAT AGC ACT GTA GAT GAT GTG TAA CAT AAA TCT CAC TGT TTA AAB 809 818 aคa

Fig. 1 Nucleotide and deduced amino acid sequences of EcPrx5 cDNA of E. carinicauda. The letters in box indicated the start codon (ATG), the stop codon (TAA) and the polyadenylation signal sequence (ATAAA). The Prx5 signature motifs (VPGAFTPGCSKTHLPG and DGTGLTCSL) were underlined and the conserved cysteines were shaded

\section{E. carinicauda \\ II. rosenbergii \\ A. aegypti \\ B. terrestris \\ $\mathrm{X}$. laevis \\ R. norvegicus \\ B. taurus \\ H. sapiens}

\section{E. carinicauda \\ M. rosenbergii \\ A. aegypti \\ B. terrestris \\ $\mathrm{X}$. laevis \\ R. norvegicus \\ B. taurus}

H. sapiens

E. carinicauda

M. rosenbergii

A. aegypti

B.terrestris

$\mathrm{X}$. laevis

R. norvegicus

B. taurus

H. sapiens

$$
\begin{aligned}
& \text { MGVPTMATILSAQ. . . VVTQIVPRFCAKS. . . . . PLGIFTALSRAMIS } \\
& \text { MATVLSAQ. . . . LTQVISRFCAKS. ........RFGVF } \\
& \text { MHPLLVQP. . . . . FASKF SLLKQLGRST. . . . SATVQRF SF HTSKMIV } \\
& \text { MNPLISRA. . . . ISVNERLS . . LG. . . . . . Y YIIRQFRVSSQNUV . }
\end{aligned}
$$

USLRIPVSFLL

MVQLRFCVLGSIAGSVLRAS. . A ATUTCVAGRAGRKGAG . . . WECGGARSFSS AAVTMIAP IKVG MRLGWLRVLGCRPGSUVSRAT IVEGASTT \& AGTRGCLEGILEWTF GGVRG MGLAGVCALRRSAGYILVGG. . . AGGQSAAAAARRCSEGE. . WASGGVRSFSRAAAMIMP I
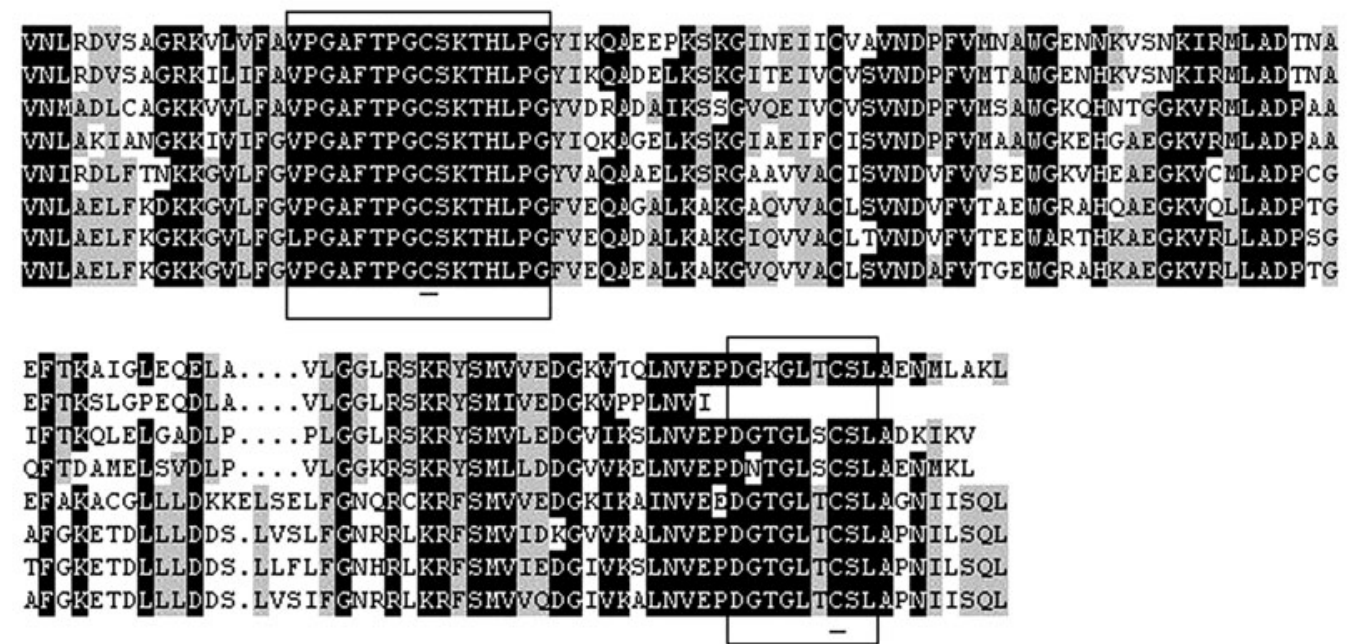

Fig. 2 Multiple alignment of EcPrx5 with other known Prx5 s: $M$. rosenbergii (HQ668096), A. aegypti (XP_001658149), Bombus terrestris (XP_003394825), X. laevis (AEM44542), Rattus norvegicus (AAH78771), B. taurus (AAG53661), H. sapiens (CAG33484).

estimated isoelectric point was 7.62. The EcPrx5 cDNA sequence has been submitted to the GenBank (GenBank accession number: JX508643).

\section{Homology analysis of EcPrx5}

Sequence analysis with the BLASTP program revealed that the deduced amino acid sequence of EcPrx5
Peroxiredoxins signatures VPGAFTPGCSKTHLPG and DGTGLTCSL were marked by frame and the two highly conserved amino acids were indicated by solid lines

exhibited similarities with Prx5 of invertebrates and vertebrates. It displayed high similarity to Prx5 of Macrobrachium rosenbergii (89\%), Megachile rotundata (68\%), Anopheles darlingi (66\%), Harpegnathos saltator (66\%), Acromyrmex echinatior (65\%), Nasonia vitripennis (64\%), Tribolium castaneum (64\%), Aedes aegypti (63\%), Papilio xuthus (62\%), Crassostrea gigas $(61 \%)$, Xenopus laevis $(55 \%)$, Danio rerio 
(53\%), Bos taurus (52\%), Homo sapiens (51\%), and so on.

Multiple sequence alignment revealed that the cysteine residue ( $\mathrm{Cys}^{83}$ and $\mathrm{Cys}^{184}$ ) was conserved in all the analyzed Prx5 s. In addition, $\mathrm{Cys}^{83}$ and $\mathrm{Cys}^{184}$, positioned within VPGAFTPGCSKTHLPG and DGTGLTCSL respectively, were deduced to form the intramolecular disulfide bond. No signal peptide was identified by the signalP program (Fig. 2).

A molecular phylogenetic tree was constructed to further analyze the evolutionary relationships among animal Prx sequences (Fig. 3). Base on MEGA 4.0 analysis, the Prxs were identified with three distinct clades, 1-Cys, 2-Cys, and atypical 2-Cys. All the Prx5s formed the atypical 2-Cys subgroup, and all the Prx6s were clustered together and formed a sister group with Prx5 s. Prx1, Prx2, Prx3 and Prx4 clustered into a branch and constituted to 2-Cys subgroup. EcPrx5 was clustered into atypical 2-Cys subgroup. In the Prx5s subgroup, the sequences from vertebrate diverged from invertebrate, and EcPrx 5 was placed in the invertebrate branch with other arthropods.

\section{Tissue expression of EcPrx 5}

Quantitative real-time RT-PCR was employed to investigate the distribution of EcPrx 5 mRNA in different tissues. The mRNA transcripts of EcPrx 5 could be detected in all the examined tissues with different expression levels including hemocytes, gill, hepatopancreas, muscle, ovary, intestine, stomach and eyestalk (Fig. 4). The highest expression was found in hepatopancreas, and the lowest was in eyestalk.

EcPrx 5 gene expression after $V$. anguillarum and WSSV challenge

The mRNA expression levels of EcPrx 5 in hemocytes and hepatopancreas of E. carinicauda after $V$. anguillarum and WSSV challenge were quantified by real-time RT-PCR with $18 \mathrm{~S}$ gene as internal control. For both EcPrx5 and 18S genes, there were only one peak at the corresponding melting temperature in the dissociation curve analysis, indicating that the PCR was specifically amplified.

The expression levels of EcPrx 5 in ridgetail white prawn hemocytes after $V$. anguillarum and WSSV challenge were shown in Fig. 5. Compared to the control, the expression of EcPrx5 in $V$. anguillarum and WSSV challenged group increased significantly and reached to the maximum at the first 12 and $6 \mathrm{~h}$ after challenge respectively, which was 1.78 and 1.52 -fold respectively of that in the control group $(P<0.05)$. Afterwards, the expression of EcPrx5 in the two groups decreased gradually, and dropped to the lowest level at $48 \mathrm{~h}$ after challenge, which was only 0.22 and

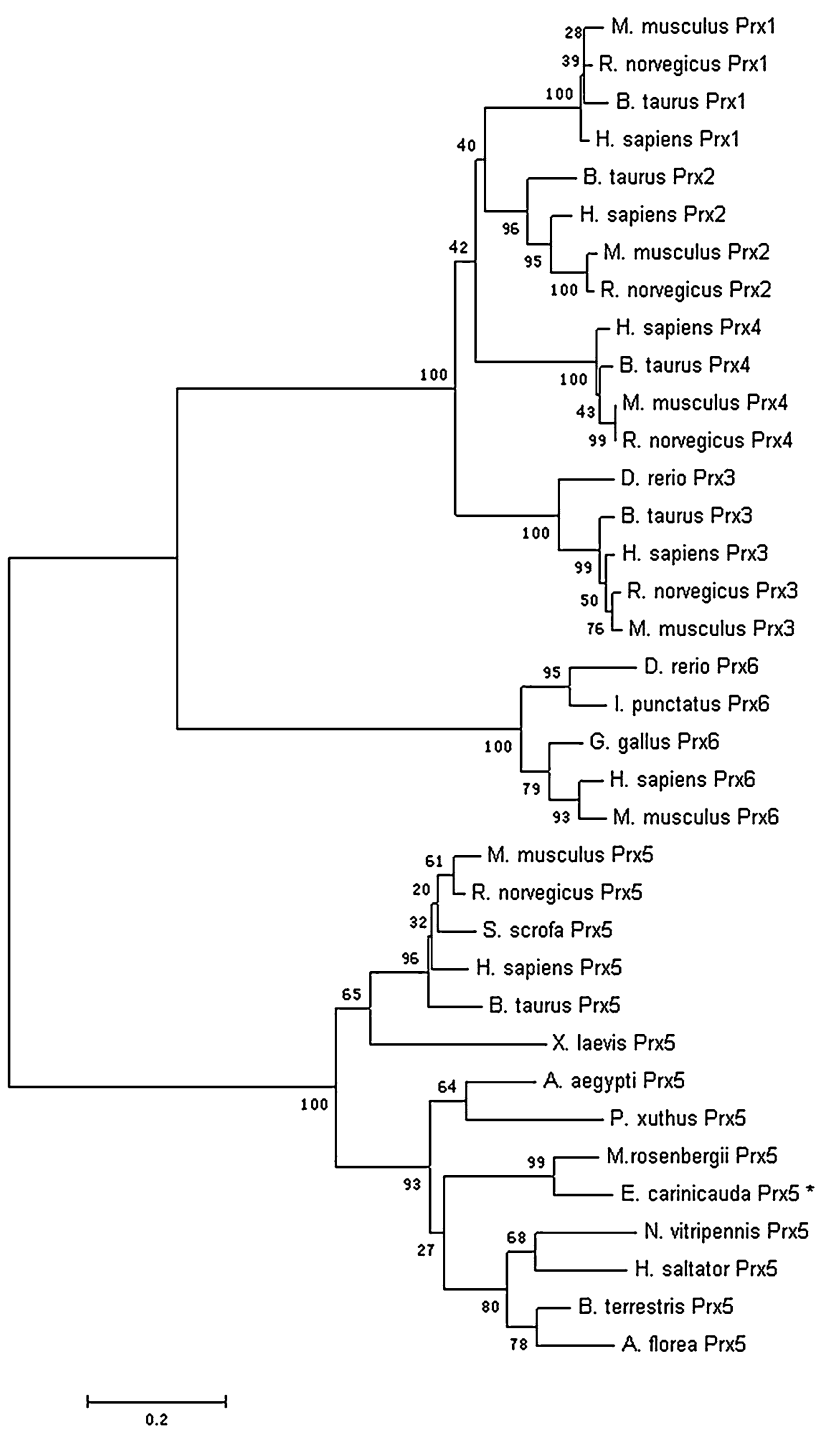

Fig. 3 Phylogenetic tree of different species Prxs on the basis of the amino acid sequence using neighbor-joining distance analysis. The numbers at the forks indicated the bootstrap. The protein sequences used for phylogenetic analysis were as follows: Prx1 from $H$. sapiens (CAG28580), Mus musculus (CAM16508), B. taurus (NP_776856) and $R$. norvegicus (NP_476455), Prx2 from H. sapiens (CAG46588), M. musculus (AAH86783), B. taurus (NP_777188) and $R$. norvegicus (NP_058865), Prx3 from H. sapiens (CAG29340), M. musculus (AAH 05626), B. taurus (NP_776857), $R$. norvegicus (EDL94585) and D. rerio (NP_001013478), Prx4 from H. sapiens (CAG46506), M. musculus (CAM23141), B. taurus (NP_776858) and $R$. norvegicus (NP_445964), Prx5 from H. sapiens (CAG33484), M. musculus (AAG13450), B. taurus (AAG53661), Sus scrofa (NP_999309), R. norvegicus (AAH78771), X. laevis (AEM44542), M. rosenbergii (HQ668096), N. vitripennis (XP_00 1603445), A. aegypti (XP_001658149), B. terrestris (XP_003394825), H. saltator (EFN85437), Apis florae (XP_003694601) and P. xuthus (BAM18222), Prx6 from $H$. sapiens (NP_004896), M. musculus (NP_031479), Gallus gallus (NP_001034418), D. rerio (NP_957099) and Ictalurus punctatus (ABG77029)

0.08 -fold respectively of that in the control group $(P<0.05)$, then recovered to 0.72 and 0.42 -fold respectively of the control at $72 \mathrm{~h}$ after challenge. 


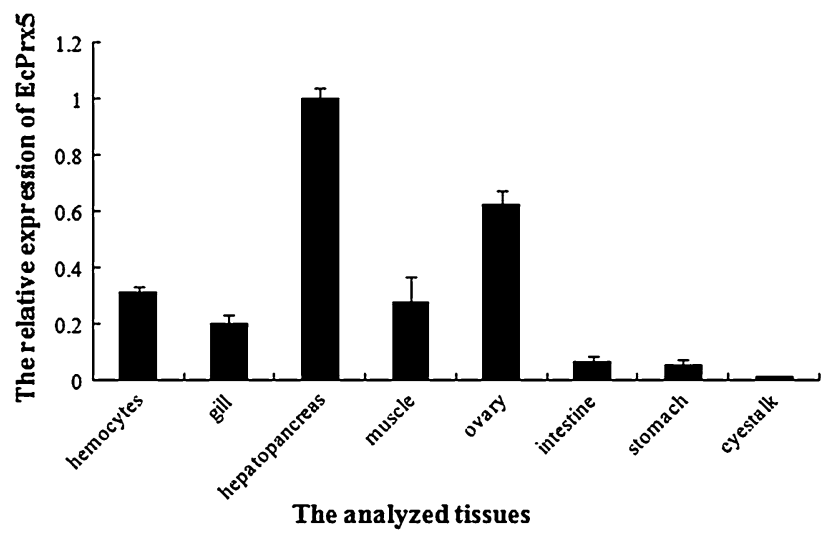

Fig. 4 Tissue specific expression of EcPrx5 mRNA related to hepatopancreas expression by the real-time PCR. The reference gene is $18 \mathrm{~S}$. Vertical bars represent the mean $\pm \mathrm{SD}(N=3)$

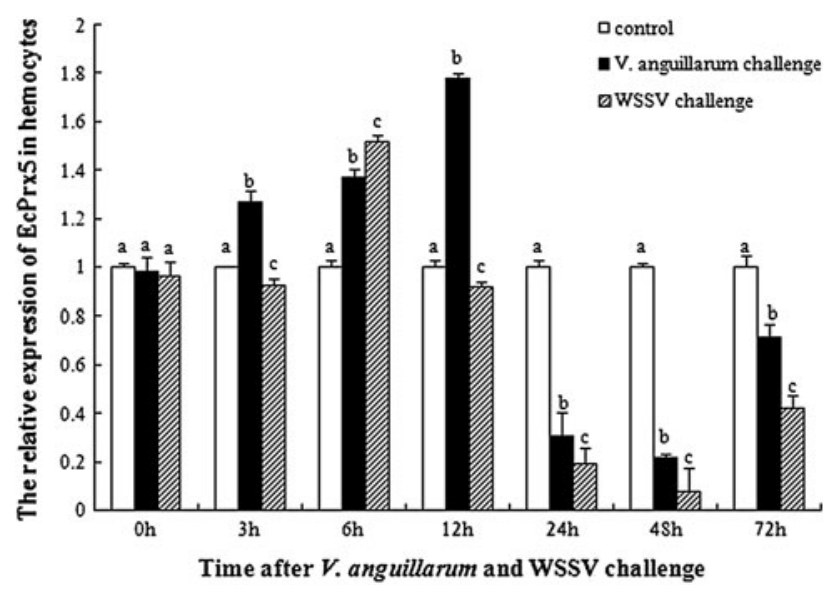

Fig. 5 The EcPrx 5 mRNA expression levels relative to $18 \mathrm{~S}$ mRNA levels analyzed by real-time PCR in haemocytes of E. carinicauda at different time intervals after $V$. anguillarum and WSSV challenge treatment. Vertical bars represent the mean $\pm \mathrm{SD}(N=3)$. Data without shared letters were significantly different $(P<0.05)$ among treatments in the same exposure time

Expression profiles of EcPrx5 in hepatopancreas after $V$. anguillarum and WSSV challenge was shown in Fig. 6. Compared to the control, the EcPrx5 mRNA expression levels of $V$. anguillarum and WSSV challenged groups increased significantly and reached the highest at $6 \mathrm{~h}$ after challenge, which was 1.71 and 1.51 -fold respectively of that in the control group $(P<0.05)$. After $6 \mathrm{~h}$ challenge, EcPrx 5 mRNA expression levels in $V$. anguillarum challenged group decreased gradually and reached to a low level at $12 \mathrm{~h}$ after challenge $(0.54$-fold of that in control group, $P<0.05$ ), then recovered to 0.71 -fold of the control at $72 \mathrm{~h}$ after challenge. However, the EcPrx 5 mRNA expression levels of WSSV challenged group decreased and reached the lowest at $48 \mathrm{~h}$ after challenge ( 0.63 -fold of that in control group, $P<0.05)$, then rised gradually and

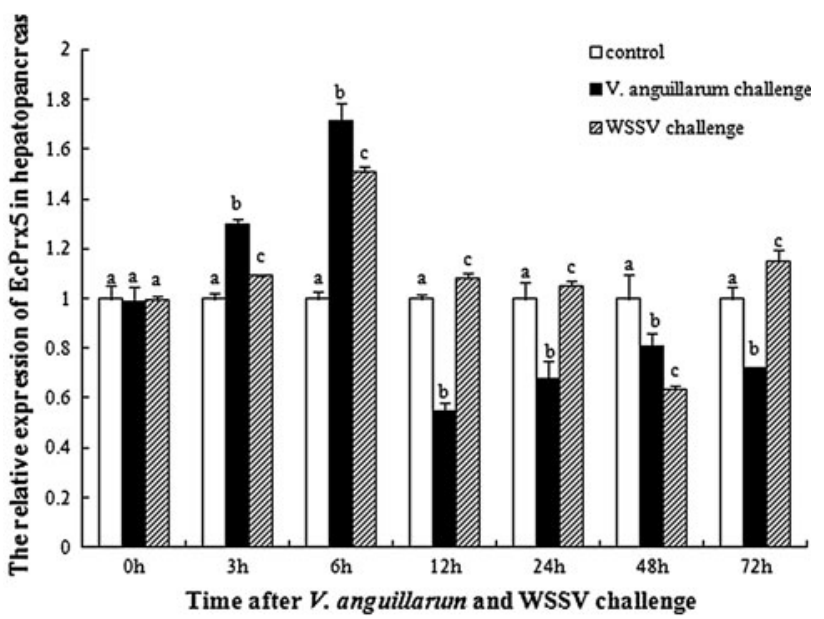

Fig. 6 The EcPrx 5 mRNA expression levels relative to 18S mRNA levels analyzed by real-time PCR in hepatopancreas of E. carinicauda at different time intervals after $V$. anguillarum and WSSV challenge treatment. Vertical bars represent the mean $\pm \mathrm{SD}(N=3)$. Data without shared letters were significantly different $(P<0.05)$ among treatments in the same exposure time

recovered to 1.14-fold of the control at $72 \mathrm{~h}$ after challenge.

\section{Discussion}

The peroxiredoxin family is an evolutionarily conserved group of antioxidants that protect cells from oxidative damage by catalyzing the reduction of a wide range of cellular peroxides [31]. In the present study, a novel Prx gene (EcPrx5) was cloned from E. carinicauda. Prior to this study, no full-length cDNA of Prx 5 has been isolated in E. carinicauda, and our study is the first report on cloning of the full-length cDNA of Prx5 in E. carinicauda. Homology analysis revealed that the deduced amino acid sequence of EcPrx 5 had more than $50 \%$ similarity with Prx 5 of other animals (89\% with M. rosenbergii, $68 \%$ with $M$. rotundata, $66 \%$ with $H$. saltator, $65 \%$ with $A$. echinatior, $53 \%$ with D. rerio and $51 \%$ with H. sapiens). Phylogenetic analysis showed a closer relationship of EcPrx5 with other animals, indicating that the EcPrx5 gene belonged to the atypical 2-Cys Prx subgroup. Multiple sequence alignment analysis revealed that two cysteines $\left(\mathrm{Cys}^{83}\right.$ and $\left.\mathrm{Cys}^{184}\right)$ are highly conserved in all of the Prx5 investigated, which located in the Prx signature motifs, and critical for enzyme function serving as a catalytic site and a resolving residue [20]. Compared to Prx5 s of other animals, the Prx signature motifs VPGAFTPGCSKTHLPG appeared to be well conserved, while the motifs DGTGLTCSL had obvious difference. At position I, threonine was replaced by lysine in E. carinicauda, and 
threonine is substituted for serine in insects at position II, the reason would be study in the future.

Quantitative real-time RT-PCR revealed that EcPrx5 was expressed in all the tested tissues, and the highest expression level occurred in the hepatopancreas. As reported by Maningas et al. [32], the differential expression of Prx in various shrimp tissues shows that it is an important molecule that could effectively be involved in a number of physiological activities. Therefore, the EcPrx 5 expressed in different tissues of E. carinicauda indicated that it could potentially be involved in different physiological process, such as ROS clearance [33, 34], cell differentiation [35, 36], proliferation [37], apoptosis [38], signal transduction [39], immune response [20, 21], and so on.

Various diseases, which mostly caused by bacteria and viruses, have affected the commercial shrimp aquaculture. Prx have been proposed to play a part in the physiological oxidative stress response to bacterial and viral infections in arthropods. Information about the expression profile of Prx5 after bacterial and viral challenge would be helpful in understanding its biological function. V. anguillarum and WSSV are both the extremely virulent pathogen prevalent causing mass mortalities and economic losses in shrimp aquaculture [40-42]. When pathogens enter into the body of the shrimp, they will encounter the innate immune systems [43] and ROS are released by oxidative stress in response to them. In the present study, live $V$. anguillarum and WSSV were chosen for challenging the shrimp, so that the shrimp health condition could be affected severely by the production of $V$. anguillarum and WSSV. The level of Prx5 transcripts in hemocytes of Argopecten irradians was up-regulated and appeared to be time-dependent after $V$. anguillarum challenged, which indicated that Prx5 is a inducible protein that plays an important role in the immune response against bacterial infection [20]. It reported that in addition to the general antioxidant role of Prx, it may also be associated with immune responses, where Prx could serve to remove ROS [44]. So, the provoked increase of Prx 5 expression level was found as one of protection approaches of organisms from further damage.

In our study, EcPrx5 expression in E. carinicauda hemocytes and hepatopancreas was up-regulated at earlier time and then decreased gradually with $V$. anguillarum and WSSV challenge. The results showed that EcPrx 5 might be involved in a transient systemic immune response to the $V$. anguillarum and WSSV stimulation. Prx5 gene expression was significantly up-regulated until $12 \mathrm{~h}$ p.i in gills and then down-regulated in the following p.i. time points at 24 and $48 \mathrm{~h}$ in IHHNV infected $M$. rosenbergii [16], which were consistent with our results. After $V$. anguillarum and WSSV challenged $6 \mathrm{~h}$, the transcripts level of EcPrx 5 in hemocytes and hepatopancreas of both the challenged group were significant higher than that in the control group, it can be deduced that the challenged shrimps would generate a mass of ROS which need to be eliminated by extra Prx translated from more Prx transcripts. As time progressed, the expression of EcPrx5 in hemocytes dropped to a low level at 24 and $48 \mathrm{~h}$ in both $V$. anguillarum and WSSV challenged group, which might because of the infection progress brought more bacterias and virus, and destroyed severely to the normal function of shrimp's cells and finally caused that the expression of EcPrx 5 in the challenged group decreased gradually [7]. EcPrx5 showed a different expression profile in hemocytes and hepatopancreas after $V$. anguillarum and WSSV challenge, this might be caused by the different function of hemocytes and hepatopancreas in the immune defense system. It has been proved that hemocytes are key cells for invertebrate's innate defense reactions $[45,46]$ and play an important role in the host immune functions when the organism is attacked by bacterias or viruses [47, 48]. This study showed that EcPrx5 may serve to decrease the cellular damage caused by $V$. anguillarum and WSSV, and the knowledge on this gene expression studies can provide useful tools in understanding and quantifying how these organisms respond to various biotic environmental stress.

In conclusion, a novel Prx cDNA (EcPrx5) was cloned from $E$. carinicauda, and it constitutively expressed in the tissues of hemocytes, gill, hepatopancreas, mucle, ovary, intestine, stomach and eyestalk. The rapid and dynamic expression profiles in hemocytes and hepatopancreas challenged with $V$. anguillarum and WSSV indicated that EcPrx5 was perhaps involved in the immune response against bacterial and viral infection. However, further work is required to better understand the regulation of antioxidant enzymes under oxidative stresses.

Acknowledgments This study was supported by the earmarked fund for National " 863 "' Project of China (2012AA10A409), Modern Agro-industry Technology Research System (CARS-47), Special Fund for Agro-scientific Research in the Public Interest (201103034) and Special Scientific Research Funds for Central Non-profit Institutes, Chinese Academy of Fishery Sciences (2013A0701).

Open Access This article is distributed under the terms of the Creative Commons Attribution License which permits any use, distribution, and reproduction in any medium, provided the original author(s) and the source are credited.

\section{References}

1. Steenvoorden DPT (1997) The use of endogenous antioxidants to improve photoprotection. J Photochem Photobio B 41:1-10

2. Bogdan C, Röllinghoff M, Diefenbach A (2000) Reactive oxygen and reactive nitrogen intermediates in innate and specific immunity. Curr Opin Immunol 12:64-76 
3. Aguirre J, Momberg MR, Hewitt D, Hansberg W (2005) Reactive oxygen species and development in microbial eukaryotes. Trends Microbiol 13:111-118

4. Yu BP (1994) Cellular defenses against damage from reactive oxygen species. Physiol Rev 74:139-162

5. Zhang QL, Li FH, Zhang JQ, Wang B, Gao HW, Huang BX, Jiang H, Xiang JH (2007) Molecular cloning, expression of a peroxiredoxin gene in Chinese shrimp Fenneropenaeus chinensis and the antioxidant activity of its recombinant protein. Mol Immunol 44:3501-3509

6. Zhang QL, Li FH, Zhang XJ, Dong B, Zhang JQ, Xie YS, Xiang JH (2008) cDNA cloning, characterization and expression analysis of the antioxidant enzyme gene, catalase, of Chinese shrimp Fenneropenaeus chinensis. Fish Shellfish Immunol 24:584-591

7. Chen P, Li JT, Gao BQ, Liu P, Wang QY, Li J (2011) cDNA cloning and characterization of peroxiredoxin gene from the swimming crab Portunus trituberculatus. Aquaculture 322-323:10-15

8. Afonso V, Champy R, Mitrovic D, Collin P, Lomri A (2007) Reactive oxygen species and superoxide dismutases: role in joint diseases. Joint Bone Spine 74:324-329

9. Mu CK, Zhao JM, Wang LL, Song LS, Zhang H, Li CH, Qiu LM, Gai YC (2009) Molecular cloning and characterization of peroxiredoxin 6 from Chinese mitten crab Eriocheir sinensis. Fish Shellfish Immunol 26:821-827

10. Chae HZ, Chung SJ, Rhee SG (1994) Thioredoxin-dependent peroxide reductase from yeast. J Biol Chem 269:27670-27678

11. Chae HZ, Robison K, Poole LB, Church G, Storz G, Rhee SG (1994) Cloning and sequencing of thiol-specific antioxidant from mammalian brain: alkyl hydroperoxide reductase and thiol-specific antioxidant define a large family of antioxidant enzymes. Proc Natl Acad Sci 91:7017-7021

12. Kiruthiga C, Rajesh S, Rashika V, Priya R, Narayanan RB (2012) Molecular cloning, expression analysis and characterization of peroxiredoxin during WSSV infection in shrimp Fenneropenaeus indicus. J Invertebr Pathol 109:52-58

13. Kang SW, Rhee SG, Chang TS, Jeong W, Choi MH (2005) 2-Cys peroxiredoxin function in intracellular signal transduction, therapeutic implications. Trends Mol Med 11:571-578

14. Rhee SG, Kang SW, Jeong W, Chang TS, Yang KS, Woo HA (2005) Intracellular messenger function of hydrogen peroxide and its regulation by peroxiredoxins. Curr Opin Cell Biol 17:183-189

15. Zheng WJ, Hu YH, Zhang M, Sun L (2010) Analysis of the expression and antioxidative property of a peroxiredoxin 6 from Scophthalmus maximus. Fish Shellfish Immunol 29:305-311

16. Arockiaraj J, Easwvaran S, Vanaraja P, Singh A, Othman RY, Bhassu S (2012) Immunological role of thiol-dependent peroxiredoxin gene in Macrobrachium rosenbergii. Fish Shellfish Immunol 33:121-129

17. Wood ZA, Schroder E, Harris JR, Poole LB (2003) Structure, mechanism and regulation of peroxiredoxins. Trends Biochem Sci $28: 32-40$

18. Nguyên-nhu NT, Berck J, Clippe A, Duconseille E, Cherif H, Boone C, der Eecken VV, Bernard AA, Banmeyer I, Knoops B (2007) Human peroxiredoxin 5 gene organization, initial characterization of its promoter and identification of alternative forms of mRNA. Biochimica et Biophysica Acta 1769:472-483

19. Declercq JP, Evrard C, Clippe A, Stricht DV, Bernard A, Knoops B (2001) Crystal structure of human peroxiredoxin 5, a novel type of mammalian peroxiredoxin at $1.5 \AA$ resolution. J Mol Biol 311:751-759

20. Li J, Li L, Zhang SD, Zhang GF (2011) Cloning, genomic structure, and expression analysis of peroxiredoxin $\mathrm{V}$ from bay scallop Argopecten irradians. Fish Shellfish Immunol 30:309-316
21. Arockiaraj J, Easwvaran S, Vanaraja P, Singh A, Othman RY, Bhassu S (2012) Immunological role of thiol-dependent peroxiredoxin gene in Macrobrachium rosenbergii. Fish Shellfish Immunol 33:121-129

22. Michalak K, Orr WC, Radyuk SN (2008) Drosophila peroxiredoxin 5 is the second gene in a dicistronic operon. Biochem Biophys Res Commun 368:273-278

23. Peng Y, Yang PH, Ng SSM, Lum CT, Kung HF, Lin MC (2004) Protection of Xenopus laevis embryos against alcohol-induced delayed gut maturation and growth retardation by peroxiredoxin 5 and catalase. J Mol Biol 340:819-827

24. Duan YF, Liu P, Li JT, Li J, Chen P (2013) Immune gene discovery by expressed sequence tag (EST) analysis of hemocytes in the ridgetail white prawn Exopalaemon carinicauda. Fish Shellfish Immunol 34:173-182

25. Li JT, Han JY, Chen P, Chang ZQ, He YY, Liu P, Wang QY, Li J (2012) Cloning of a heat shock protein 90 (HSP90) gene and expression analysis in the ridgetail white prawn Exopalaemon carinicauda. Fish Shellfish Immunol 32:1191-1197

26. Xu WJ, Xie JJ, Shi H, Li CW (2010) Hematodinium infections in cultured ridgetail white prawns, Exopalaemon carinicauda, in eastern China. Aquaculture 300:25-31

27. Söderhäll K, Smith VJ (1983) Separation of the haemocyte populations of Carcinus maenas and other marine decapods. Dev Comp Immunol 7:229-239

28. Tamura K, Dudley J, Nei M, Kumar S (2007) MEGA 4: molecular evolutionary genetics analysis (MEGA) software version 4.0. Mol Biol Evol 24:1596-1599

29. Li MY, Li J, Liu P, Li JT (2012) Cloning and expression analysis of ferritin gene in Exopalaemon carinicauda. Oceanologia Et Limnologia Sinica 43:306-312 [In Chinese]

30. Livak KJ, Schmittgen TD (2001) Analysis of relative gene expression data using real-time quantitative PCR and the 2 (delta delta $\mathrm{C}(\mathrm{T})$ ) method. Methods 25:402-408

31. Dayer R, Fischer BB, Eggen RIL, Lemaire SD (2008) The peroxiredoxin and glutathione peroxidase families in Chlamydomonas reinhardtii. Genetics 179:41-57

32. Maningas MBB, Koyama T, Kondo H, Hirono I, Aoki T (2008) A peroxiredoxin from kuruma shrimp, Marsupenaeus japonicus, inhibited by peptidoglycan. Dev Comp Immunol 32:198-203

33. Banmeyer I, Marchand C, Clippe A, Knoops B (2005) Human mitochondrial peroxiredoxin 5 protects from mitochondrial DNA damages induced by hydrogen peroxide. FEBS Lett 579:2327-2333

34. Yuan J, Murrell GA, Trickett A, Landtmeters M, Knoops B, Wang MX (2004) Overexperssion of antioxidant enzyme peroxiredoxin 5 protects human tendon cells against apoptosis and loss of cellular function during oxidative stress. Biochim Biophys Acta (BBA)-Mol. Cell Res 1693:37-45

35. Rabilloud T, Berthier R, Vincon M, Ferbus D, Goubin G, Lawrence JJ (1995) Early events in erythroid differentiation: accumulation of the acidic peroxidoxin (PRP/TSA/NKEF-B). Biochem J 312:699-705

36. Kawai S, Takesita S, Okazaki M, Kikuno R, Kudo A, Amann E (1994) Cloning and characterization of OSF-3, a new member of the MER5 family, expressed in mouse osteoblastic cells. J Biochem 115:641-643

37. Prosperi MT, Ferbus D, Karczinski I, Goubin G (1993) A human cDNA corresponding to a gene overexpressed during cell proliferation encodes a product sharing homology with amoebic and bacterial proteins. J Biol Chem 268:11050-11056

38. Kropotov A, Gogvadze V, Shupliakov O, Tomilin N, Serikova VB, Tomilind NV (2006) Peroxiredoxin V is essential for protection against apoptosis in human lung carcinoma cells. Exp Cell Res 312:2806-2815 
39. Seo MS, Kang SW, Kim K, Baines IC, Lee TH, Rhee SG (2000) Identification of a new type of mammalian peroxiredoxin that forms an intramolecular disulfide as a reaction intermediate. J Biol Chem 275:20346-20354

40. Toranzo AE, Magarinos B, Romalde JL (2005) A review of the main bacterial fish diseases in mariculture systems. Aquaculture 246:37-61

41. Lightner DV, Hasson KW, White BL, Redman RM (1998) Experimental infections of western hemisphere Penaeid shrimp with Asian white spot syndrome virus and Asian yellow head virus. J Aquat Anim Health 10:271-281

42. Spann KM, Lester RJG (1997) Special topic review: viral diseases of penaeid shrimp with particular reference to four viruses recently found in shrimp from Queensland. World J Microbiol Biotech 13:419-426

43. Soonthornchai W, Rungrassamee W, Karoonuthaisiri N, Jarayabhand P, Klinbung S, Söderhäll K, Jiravanichpaisal P (2010)
Expression of immune-related genes in the digestive organ of shrimp, Penaeus monodon, after an oral infection by Vibrio harveyi. Dev Comp Immunol 34:19-28

44. Vazquez L, Alpuche J, Maldonado G, Agundis C, Pereyra-Morales A, Zenteno E (2009) Immunity mechanisms in crustaceans. Innate Immunol 15:179-188

45. Iwanaga S, Lee BL (2005) Recent advances in the innate immunity of invertebrate animals. $\mathrm{J}$ Biochem Mol Biol 38:128-150

46. Lavine MD, Strand MR (2002) Insect hemocytes and their role in immunity. Insect Biochem Mol Biol 32:1295-1309

47. Lee S, Söderhäll K (2002) Early events in crustacean innate immunity. Fish Shellfish Immunol 12:421-437

48. Smith VJ, Brown JH, Hauton C (2003) Immunostimulation in crustaceans: does it really protect against infection? Fish Shellfish Immunol 15:71-90 